\title{
Pneumonitis, pleural effusion and pericarditis following treatment with dantrolene
}

\author{
DH MILLER, LF HAAS \\ From the Neurology Department, Wellington Hospital, Wellington, New Zealand
}

SUMMARY A patient developed pulmonary infiltration, pleural effusions and pericarditis three months after starting dantrolene sodium. Peripheral blood eosinophilia and a raised ESR were present. Symptoms and signs resolved after the drug was discontinued. Dantrolene toxicity should be considered in the differential diagnosis of pneumonitis and pleuro-pericarditis.

Use of dantrolene sodium (dantrium) to lessen spasticity can be limited by hepatic toxicity.' There has also been one report of potentially serious pleuropericardial reactions. ${ }^{2}$ We describe a further case with pulmonary parenchymal involvement in addition to pleuro-pericardial reaction.

\section{Case report}

A 43-year-old female suffered from multiple sclerosis since 1973. By January 1983 she had bilateral optic atrophy, horizontal and vertical nystagmus, incoordination of the upper limbs, marked spasticity and weakness of the lower limbs with frequent painful spasms. Baclofen 80 $\mathrm{mg} /$ day combined with physiotherapy made little difference to her spasticity or spasms. Dantrolene was then introduced in late January 1983 , increasing to $100 \mathrm{mg}$ qid. Chest radiograph prior to treatment was normal.

Two months after starting dantrolene pleuritic pains in the left shoulder and chest occurred without other respiratory symptoms. Temperature was $38 \cdot 2^{\circ} \mathrm{C}$. Breath sounds were reduced at the left base, along with dullness and decreased tactile fremitus. Chest radiograph showed a left basal opacity. The left leg was swollen and venography demonstrated a left deep venous thrombosis. Perfusion lung scan was negative. Despite physiotherapy and amoxycillin, the fever, opacity and pleuritic pain persisted. Three months after starting dantrolene she developed precordial pain worse with inspiration. Temperature was $38.2^{\circ} \mathrm{C}$, and pulse rate $120 / \mathrm{min}$. Dullness with reduced breath sounds were now present at both lung bases. ECG showed wide spread ST elevation typical of pericarditis and chest radiography showed bilateral pleural opacities with

Address for reprint requests: Dr DH Miller, National Hospital for Nervous Diseases, Queen Square, London WC1N 3BG, UK.

Received 21 October 1983. Accepted 18 November 1983

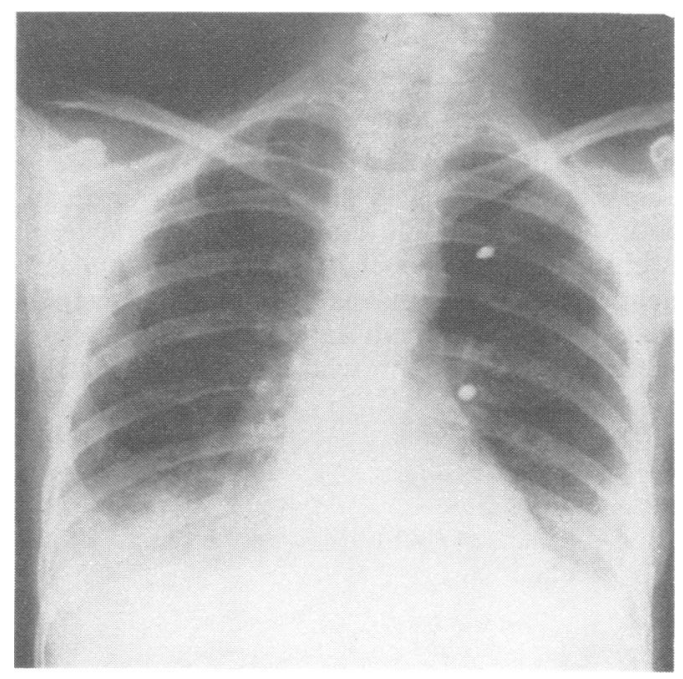

Fig. Chest radiograph 3 months after starting dantrolene showing bilateral basal opacities with pleural effusions.

bilateral effusions (fig). Hb was $10.9 \mathrm{~g} / \mathrm{dl}$, white count 10.0 $\times 10^{9} / 1$ with $15 \%$ eosinophils, ESR $87 \mathrm{~mm} / \mathrm{h}$, antinuclear factor weakly positive to 1 in 10 . Liver function tests were normal.

Dantrolene was discontinued. After three months the symptoms resolved and the chest radiograph returned to normal as did the white count. ESR fell to $41 \mathrm{~mm} / \mathrm{h}$ but there was an associated urinary tract infection.

\section{Discussion}

When this patient first developed fever and pleuritic chest pain with radiological evidence of left lower lobe infiltration hypostatic pneumonia was consi- 
dered likely, but the patient failed to respond to physiotherapy and antibiotics. Pulmonary embolism was also suspected, particulary with a coincident deep vein thrombosis, but isotope perfusion lung scan was negative. Subsequently the picture of a more chronic pulmonary and pleural disorder developed as well as acute pericarditis with appropriate ECG changes. The development of this illness associated with eosinophilia soon after commencing dantrolene and subsequent improvement on stopping the drug suggested the illness was a complication of dantrolene therapy.

Pleuro-pericardial reactions can occur as part of a drug induced lupus syndrome. ${ }^{34}$ Low titre of antinuclear antibodies in this case made lupus improbable. Drugs associated with pleuro-pericardial reactions (non lupoid) include practolol, ${ }^{5}$ methysergide ${ }^{6}$ and bromocriptine. ${ }^{7}$ Petusevsky et $a l^{2}$ described four cases of pleuro-pericardial reaction to dantrolene. They emphasised the structural similarity of dantrolene with nitrofurantoin. The latter is a well recognised cause of acute and chronic pleuro pulmonary reactions. ${ }^{89}$ Pulmonary involvement was not a feature of the four cases of Petusevsky et al. In this respect the present case differs. The four cases of Petusevsky et al showed eosinophilia of peripheral blood and pleural fluid and in two pleural biopsy demonstrated non specific fibrosis. This emphasises a need for early diagnosis to prevent irreversible damage. It would be advisable to discontinue dantrolene in any patient who develops clinical or radiological evidence of pleural, pulmonary or pericardial disturbance, especially when more usual aetiological factors cannot be implicated.

\section{References}

' Utili R, Boitnott JK, Zimmerman HJ. Dantroleneassociated hepatic injury. Incidence and character. Gastroenterology 1977;72:610-6.

${ }^{2}$ Petusevsky ML, Faling LJ, Rocklin RE, Snider GL, Merliss AD, Moses JM, Dorman SA. Pleuropericardial reaction to treatment with dantrolene. JAMA 1979;242:2772-4.

${ }^{3}$ Swarbrick ET, Gray IR. Procainamide-induced systemic lupus erythematosus. Rheumatol Phys Med 1973;12:94-5.

${ }^{4}$ Singsen BH, Fishman L, Hanson V. Antinuclear antibodies and lupus-like syndromes in children receiving anticonvulsants. Pediatrics 1976;57:529-34.

5 Dyer NH, Varley CC. Practolol-induced pleurisy and constrictive pericarditis. Br Med J 1975;2:443.

${ }^{6}$ Hindle W, Posner E, Sweetnam MT, Tan RSH. Pleural effusion and fibrosis during treatment with methysergide. $\mathrm{Br}$ Med J 1970;1:605-6.

${ }^{7}$ Le Witt PA, Calne DB. Recent advances in the treatment of Parkinson's disease: the role of bromocriptine. J Neural Transm 1981;51:175-84.

${ }^{8}$ Israel HL, Diamond P. Recurrent pulmonary infiltration and pleural effusion due to nitrofurantoin sensitivity. N Engl J Med 1962;266:1024-6.

${ }^{9}$ Rosenow EC III, DeRemee RA, Dines DE. Chronic nitrofurantoin pulmonary reaction. Report of five cases. N Engl J Med 1968;279:1258-62. 